\title{
The Aristotelian Perspective in Otakar Zich's The Aesthetics of Dramatic Art
}

Petr Osolsobě

\begin{abstract}
In parallel with the Prague School, Otakar Zich's The Aesthetics of Dramatic Art $(1931,1986)$ shows notable methodological affinity with Aristotle's treatment of the art of drama, item (1) systematic and analytical approach to theatre; (2) mimetic theory of drama; (3) hylomorphic explanation of the 'actor-figure'; (4) active role of a viewer in forming mental images; (5) analysis of dramatic relations and the whole of fictional action. Proceeding point by point, I look for both similarities to and differences from Aristotle's theory of art and drama, and explore the theoretic presuppositions of Otakar Zich's chef d'oeuvre.
\end{abstract}

\section{Key words}

Otakar Zich (1879-1934), drama, aesthetics of arts, Aristotle, Ivo Osolsobě (1928-2012), semiotics, Prague School, epistemology 
In the past, my father Ivo Osolsobě, Otakar Zich's translator, editor, interpreter and a life-long devotee, and myself had many discussions concerning a certain undercurrent of Aristotelian inspiration in Czech science between the wars. Various theoreticians re-invented Aristotle's modes of thinking in rather unexpected ways seemingly intuitively and unwittingly, i.e. without a direct reference to or a closer knowledge of Aristotle's original texts. Karel Engliš, the first rector of the at-the-time newly founded Masaryk University in Brno and an influential economist and theoretician, was one of them, and his Teleology as a Form of the Scientific Knowledge (1930) was widely read in the Prague Linguistic Circle. ${ }^{1}$ Thus, via Engliš, the Aristotelian concept of the final cause (telos) was influential on the interpretation of the term function along with the 'Meanand-Goal' approach to linguistics and aesthetics (Jakobson, Mukařovský, and Veltruský inter al.). The preference for a teleological explanation of nature, language and art itself by way of the concept of 'function', the systematic exploration of 'structures', as well as the denial of any purely historical standpoint, are all manifested in the qualities of the Circle's constructivism. In such a view, art-works are made of signs, i.e. they should be studied as purposely constructed realities, not as immediate expressions of consciousness. In this article, we attempt to argue that Otakar Zich's The Aesthetics of Dramatic Art $(1931,1986)^{2}$ also shows a notable methodological affinity with Aristotle's treatment of the art of drama, namely in the following points: (1) a systematic and analytical approach to theatre; (2) a mimetic theory of drama; (3) a hylomorphic explanation of the 'actor-figure'; (4) the active role of a viewer in forming mental images; and (5) its analysis of dramatic relations and the whole of fictional action.

Oddly enough, in the 1920s and 1930s, Aristotle was not a generally popular author among aestheticians, except for the Neo-Thomists. Continental philosophy was still very much preoccupied with the inheritance of Kant and Hegel, and of course with Marxism grown straight from the roots of Hegelian 'dialectics'. In the field of aesthetics, Jan Mukařovský successfully combined the terminology of both Hegel and Kant in introducing such terms as 'dialectical antinomies' for a description of unresolved tensions between two opposites in a work of art. Generally, Hegel's influence grew predominant in the Prague Linguistic Circle, with Veltruský considering Hegel's treatise of the art of drama contained in Vorlesungen über die Aesthetik III. 'the most insightful ever written' (VELTRUSKÝ 1999: 8) of Hegelianism. In the works of Otakar Zich we find no considerable influence of Hegel, and as for Immanuel Kant we find only one superfluous

1 For further details, see (OSOLSOBĚ 2003). Original title: Karel Engliš. 1930. Teleologie jako forma vědeckého poznání.

2 Otakar Zich's The Aesthetics of Dramatic Art (Estetika dramatického umĕní) was first published in 1931. This article refers to the 2nd edition (Praha: Panorama, 1986). An English translation completed by Samuel Kostomlatský and Ivo Osolsobě in the 1970s has never been published. Kostomlatský translated the term významová predstava obrazová as pictural image. Ivo Osolsobě suggested meaning image, and Mirek Čejka significatory image. Ambros and others use semantic image, Volek uses semantic representation, Drozd, Drábek and Kačer simply, the image. I settled on referential image in contrast to technical image, both concepts referencing the significant mental image (významová představa). For the purpose of this article, I follow Kostomlatskýs translation (manuscript) along with Ivo Osolsobě's emendations, with slight alterations for stylistic and grammatical purposes. 
terminological borrowing in his 'theatrical antinomies' (ZICH 1986: 30). Though Zich was steeped in philosophy as well as the fact that he was a trained mathematician, his The Aesthetics of Dramatic Art is completely devoid of cross-references to philosophy, and it is curious that Aristotle is mentioned only once ${ }^{3}$ in such a monumental theoretical work. The reason is that Zich almost always proceeds analytically, or 'empirically', much in the sense of his teacher Otakar Hostinský (1847-1910), the founder of the seat of Aesthetics at Charles University in Prague, thus all of Zich's digressions, excursions and notes supply no more than further empirical illustrations or systemic specifications. Nevertheless, the scarcity of references to Aristotle and his Poetics does not preclude the implicit Aristotelian motifs and overall perspective extant in Zich's Aesthetics. Moreover, it is perhaps inevitable for an author composing a new drama theory to engage with Poetics and to come to terms with the ideas therein.

\section{Systematic and analytical approach}

In the first chapter of The Aesthetics of Dramatic Art, Zich stipulated two basic definitions: 'The dramatic work consists of two simultaneous, inseparable, and concrete components of a different character, namely the visual or optical component and the audible or acoustic element' (ZICH 1986: 18-19). This statement must be supplemented by a closely related second principle: 'A necessary condition of the existence of a dramatic work is its real stage performance, i.e. enactment by actors on a stage' (ZICH 1986: 18-19). Thus Zich draws a line between dramatic art, on the one hand, and literature and music, on the other hand. Direct sensorial perception is thus indicated as a necessary condition, otherwise we fall into errors 'such as ranking drama as poetry and opera as music' (ZICH 1986: 19).

Here lies the salient difference from Aristotle's view of drama, which is essentially a kind of poetry and may achieve its artistic goal in a mind of a reader in his reading of it. The difference between drama and other literary genres consists in the manner of representation (mimesis), even if they represent the very same things: epic poetry by narrating (diegesis), drama by representing living beings as in action and in activity (ARISTOTLE 1987: 3). In Zich's account of the art of drama, the actor and stage-director take the central position, a space once occupied by the poet as a creator of drama. Zich's first and most fundamental purpose in writing his Aesthetics was the rightful appreciation of the actor's contribution to dramatic art, i.e. the actor's creative (and not only reproductive) performance. ${ }^{4}$ Nevertheless, two structural similarities emerge concerning Aristotle's poet and Zich's actor.

3 Here (ZICH 1986: 41), Zich briefly touches upon the problem of catharsis, which he tries to resolve by employing the 'principle of functional pleasure' from the writings of Abbé Dubos, who describes the purpose of art as to replace our harmful natural emotions with artificial ones, making them harmless, and thereby 'to purify them'. This is surely a non-Aristotelian explanation of catharsis, as Aristotle specifically points out pity and terror as the primary as well as appropriate emotions which are purified only by seeing a dramatic representation in the development of his theory of bringing our emotions closer to a virtuous mean.

4 See Zich's letter to Bohumil Novák (NOVÁK 1933: 465-469). 
Firstly, Zich emphasizes the sensorial factor for the audience as well as for the actor: (a) the dramatic persona means for the audience a sum of sensory perceptions; and (b) the performing actor maintains a vivid haptic impression of the actorfigure (which is his own creation, a sign of the dramatic character made out of the actor's own body and voice). We can see that Aristotle describes the work of poet in similar terms:

In constructing his plots and using diction to bring them to completion [the poet] should place [the events] before his eyes as much as he can. In this way, seeing them very vividly as if he were actually present at the actions [he represents], he can discover what is suitable [...] As far as possible [the poet should] also bring his plots to the completion of wish gestures. Given the same nature, those [poets] who experience the emotions are most believable. (ARISTOTLE 1987: 22)

This is, at least partially, the task of poet qua actor and the reason why he should attempt to combine the traits of genius with those of madman (ARISTOTLE 1987: 22). Mutatis mutandis, Zich employs James-Lange's theory of emotion in describing the role of the actor's phantasy in the fulfilment of his task as if the actor is to be a kind of poet, i.e. a creator.

Secondly, Zich as well as Aristotle underlines the interactive character of dramatic art in the cooperation and interplay; for Zich the interplay consists of actors in the scene, whereas for Aristotle drama represents a human interaction on the level of dramatic characters and/or inside themselves. Such a categorical difference has serious consequences for the definition of the dramatic plot which Zich strove to overcome, as we shall see later. These differences, however, should not hinder us from seeing the common theoretical ground: both Aristotle and Zich analyse dramatic art from a systematic viewpoint, and both identify its essential structure in functional synchrony. For Zich, the drama is not merely a kind of quantitative synthesis of various arts (music, design, literature, acting). Such a synthetic theory of drama remains unproductive until we have discovered the essence, the dramatic principle itself: 'Dramatic plot are events that result from the mutual interactions of the personas' (ZICH 1986: 54).

'[The] dramatic persona is a person that interacts with the other personas' (ZICH 1986: 54). For Aristotle, dramatic art is also organized as a hierarchy of various quantitative parts, of which only one is essential and leading, the dramatic plot (mûthos), with the other components more or less dependent as well as more or less elaborated (characters, reasoning, diction, scenography and music). Roughly speaking, there is one and only one 'dramatic principle' for both Aristotle and Zich, the interaction of actors on the stage (Zich), which is inseparable from the interaction of dramatic characters in the story/plot (Aristotle). 


\section{Mimetic theory of drama and Zich's principle of stylization}

We have already mentioned that Aristotle remained unpopular among aestheticians in the first half of the 20th century, and that above all because of his mimetism, i.e. the description of the relation between the real world and the fictional world as a kind of mimesis. The very term mimesis, however, used to be mistranslated as imitation [instead of representation], a rendering which seemed too narrow for the varieties and experiments of the modern art typified in Symbolism, Cubism, Abstract Painting, Dada or Surrealism. Recent editions of Aristotle's Poetics, i.e. from the 1980 Dupont-Roc's and Lallot's French translation onward, convey mimesis as representation, a translation which generally covered the "whole range of what we call copying, imitation, impersonation and representation' (JANKO in ARISTOTLE 1987: 220), or in terms of semiotics, all kinds of signs, i.e. icons, indices, symptoms, symbols, etc. In this way, even modern abstract art is not excluded from the mimetic if we find its respective modus significandi, i.e. a specific mode of signification.

Aristotle opens his Poetics with his famous definition of mimesis and the division of the concept according to media, objects and manners. Zich's Aesthetics ends with a chapter on the principle of stylisation, thus Zich seems at the beginning to detour in order to leave the crucial problem of representation until the closing chapter of his work.

Zich denies the pretensions of Naturalism which aim at the close and 'mechanical' similarity between the real and the fictional world. Nevertheless he still builds on correspondences between the inner and the outer world from the perspective of a viewer. Naturalism refuted, Zich finds in Realism a 'fully artistic tendency' (ZICH 1986: 278), as besides similarity it brings into a representation a lot of the artistic transformation of ordinary reality. The opposite extreme to Naturalism is for Zich 'Idealism', in which the relation to the real world is attenuated to near non-existence. Eventually, Zich's postulates the golden mean of the 'relative realism': the technical components of a dramatic work must resemble some phenomena observed in nature and particularly in life, but the degree of resemblance is arbitrary (ZICH 1986: 279).

Further on Zich resolves the problem of the 'theatrical illusion' (the term he finds unsatisfactory) in the following: "The essence of the "theatrical illusion" lies in the theatrical intention, which, being a kind of intention for meaning, suppresses the sense of reality and link's the spectator's sensory perception to the double-natured image: technical and referential' (ZICH 1986: 285). In addition to his first statement about the nature of the theatrical illusion Zich formulates a 'law of subjective realism': 'the similarity [between the dramatic object and our own experience] is only subjective [...] an object must appear similar, not necessarily to be similar' (ZICH 1986: 293). Thus Zich postulates a kind of minimal, sufficient and meaningful similarity to objects, persons and situations in the real life, and moreover, a similarity which must be from a particular point of view (e.g. subjective, psychological).

This may seem like a derivative from a sort of Kantian noetic (phenomena, Erscheinungen), but it is not. It is in full accord with Aristotle's principle of endoxa (likely plausible statements). Aristotle frequently discusses what seems to be so, a category explored in Top- 
ics in the treatment of a fortiori arguments: 'if that which has the greater appearance of being an attribute of the subject is not in fact an attribute of it, nor will that which has the lesser appearance of being an attribute be one' (ARISTOTLE in EVANS 1977: 84). Zich concurs Aristotle in terms of steering a way between two extremes toward a type of 'relative realism'. On the one hand Zich is relativist: in order to be mimetic, a representation must be mimetic to someone's intentional expectation of meaning. On the other hand he is a realist, even a naturalist, who recognizes that to be objectively similar is not be similar in the mind of any given person.

Zich's conception of a 'sufficient similarity' between a scenic 'realism' and 'idealism' was, in fact, as close as it could be to the Aristotle's view of mimesis as a genus proximus of all and every art, through which similarity is taken as an auxiliary concept which serves to limit and exclude wholly implausible representations, not an artistic requirement or a norm, let alone the aesthetic ideal of naturalism.

The concept of 'theatrical intention' directed towards meaning is to be compared with Aristotle's concept of intention to a purpose in which the value (telos) is identified with meaning. It is our search for meaning, which is a self-directing and auto-correcting force driving the act of aesthetic perception and keeping it firmly on the track of relative similarity with what we know from our experience and from our probabilistic imagination.

\section{Hylomorphic explanation of the relation between actor-figure / dramatic persona}

Zich clearly uses the Aristotelian distinction of matter and form, which are complementary in one physical artefact (hylomorphism), for the explanation of the nature of acting. 'An artist forms from a given material a certain work representing a certain thing. Thus: a sculptor makes, let us say, from marble a statue representing, say, Heracles. The actor makes from himself a figure representing, say, Macbeth' (ZICH 1986: 44). The art of acting is disposed in one material only, a living human. Because the artist (actor) and his material (body and voice) are so close as if merged into one, we tend to (mistakenly) identify actor with his work, i.e. histrionic or actor-figure, which is neither the actor himself, nor the dramatic persona his figure represents, but the actor-figure as such. The figure is not the actor alone but the already 'trans-formed actor', the only difference consisting in the fact that this forming is accomplished by the actor himself, that is by him who is formed and performing at the same time.

What a viewer perceives on the stage is not the motion of an actor, but his product, an actor-figure in action. 'The difference between the acted character (actor-figure) and the dramatic persona may therefore be simply stated as follows: the figure is which the actor produces, the persona is that which is seen and heard by the audience' (ZICH 1986: 57).

According to Ivo Osolsobě, the concept of actor-figure interposed between the concept of actor and that of dramatic persona is of great theoretical value and critical usage, for it opens ways to the appreciation of the actor's creative achievement (Osolsobě 
2007: 207). Moreover, this is for Zich's theory a step out from the frame of associationist psychology toward a real theatre semiotics which considers the actor (an artist) as transforming his own body (matter, hyle) a complex sign, i.e. 'actor-figure' (a form, morfe). Nevertheless, from the standpoint of the viewer (the basic perspective of the whole of Zich's Aesthetics), the actor-figure is a complex visual and auditory percept, that is a matter only, for his (onlooker's) formative act. It is the artist's task to form up from the procession of percepts coming from the stage (actor-figure, hyle) a meaningful referential image, i.e. dramatic personality (a form, morfe) in his own mind according to reason and experience. In these passages from The Aesthetics of Dramatic Art new discoveries of theatre anthropology, social psychology and cybernetics of communication are already within easy reach. 'The actor is an artist representing a thought of a person of himself' (ZICH 1986: 48).

\section{The active role of the viewer}

As we have already emphasized, both Zich and Aristotle in their respective theoretical outlines attribute a great deal of formative activity in the process of art to the viewer/ reader himself. In addition, in Zich's account of aesthetic perception it is possible to find general features of Aristotelian epistemology. Sensory data (aisthemata) provide us with material for our perception and their presence in the field of our attention merely provides us an occasion for accomplishing our own act of perception (aisthesis). We must form what comes from affected senses into images (phantasmata) according to our experiences. Zich explains in detail that:

the dramatic person is for the audience the sum of all the optical and acoustic onlooker's perceptions related to the most constant perception, namely that of the physical appearance of the person. This sum of sensorial perceptions, called forth in us from outside, is supplemented by our inward sensorial feelings resulting from our own identification with the dramatic person in question, from our instinctive imitation of the person's attitude, movement, and speech. This motoric set of sensations imparts, as we have stated before, to our impression of the dramatic person extraordinary vividness and plasticity, which is particularly typical of dramatic perceptiveness. Of the greatest significance, however, is the fact that this set of inward sensorial feelings enables us to penetrate into the inside of the dramatic person, into his or her emotions and endeavours; not into the thoughts - here the only reliable guide, as we know from the analysis of the dramatic text, is the speech. (ZICH 1986: 91)

From the above rendition of the viewer's perception Zich proceeds to ascertain the dramatic effect of a work, which 'depends practically only on the factor of association, that is in which degree it is capable of evoking associated images in us in conformity with psychological laws. This means that these images must pre-exist in us. They represent all our previous experiences acquired outwardly and inwardly' (ZICH 1986: 93). In 
his analysis of 'the associative factor' Zich attributes to the viewer the task of forming a significant mental image: the viewer interprets mimic and gestures, both natural and conventional ones, deciphers the signs and symptoms of feelings and strivings, and understands various speech-acts. Thus the dramatic person appears to us in the end to be the product of 'three syntheses' accomplished by the onlooker. Two of these spring from the attitude assumed by the actor, namely his static and dynamic characteristics, while the third is the reflection on the content of his speeches. The 'static characteristics' involve his appearance and apparel, the 'dynamic' ones his movements and mimics, with these two supplemented by the third, textual-speech characteristic. The mutual consistency of these characteristics is a relative aesthetic requirement only, since their inconsistencies are often the main source of an actor's comedy in a comedic performance: 'The greatest effect of the comic is achieved by the incoherences of these three characteristics' (ZICH 1986: 106).

Here we have another reason for a comparison with Aristotle, who discusses character (ethos) in relation to the plot of the tragedy (ARISTOTLE 1987: 16) and stipulates some general requirements for the tragic character (ARISTOTLE 1987: 19-20), the latter of which should be (1) good, (2) appropriate, (3) life-like, and (4) consistent. The fourth requirement states that if 'the model for the representation is someone inconsistent, and such a character is intended, even so it should be consistently inconsistent' (ARISTOTLE 1987: 19, emphasis added). This corresponds to Zich's 'relative' requirement of consistency as stated above. More strikingly, it also resonates with Zich 'principle of stylization' as it is expressed in the homonymous closing chapter of his work. A stylization, once artistically chosen and accepted, must be kept uniform and continuous in each and every part of the dramatic performance, be it the task of actor, director, stage designer or music composer (ZICH 1986: 300-309). Here, Zich intends the 'technical', not the 'referential' (meaning oriented) aspect of stylization. Here, regardless of a represented meaning, the actor's performance remains within the 'three laws of actor's logic'.

For the total, acoustic and optical, accomplishment of an actor, which is the postulate of totality of acting, we do not find any analogical 'mother art' as in the case of the text. The conformity of the two above components is determined from the technical point of view by the law of coordination of the inward sensorial impulses, the personal continuity by the law of continuity in the actor's person, the connection in acting by the law of exteriorization of the inward sensory impulses, i.e. by the three laws of the logic of acting, known to us from chapter IV. The physiological laws of the bodily movement lead the actor instinctively towards a stylization of his performance, implying a certain regularity, which manifests itself primarily in the tendency to introduce periodicity of repetition (breathing, walking, etc.). (ZICH 1986: 301-302)

The stylization in the actor's mimicry induces spectators toward an unnamable mood, a process which is specifically mimic, and close to the art of dance or music (ZICH 1986: 303). 
As for the semantic aspect of the actor-figure, this is an expression of a dramatic person, and to determine how this expression is understood by the public in each member's 'referential image' (významová prédstava obrazová), we have to discuss dramatic plot and action, of which character is a component and derivative.

\section{Analysis of dramatic relations and the whole of a fictional action}

Zich analyses dramatic action in Chapter VI of his Aesthetics titled 'Dramatic action: The first tasks of the Director' (the second being stage-directing), a section of the work which opens with an implicit dialogue with Aristotle and certain streams of dramatic theory from Poetics.

What is of utmost importance in the dramatic work, the dramatic person or the dramatic action? This long-lasting conflict of theorists in literature is characteristic of the 'textual approach' to the drama. (ZICH 1986: 132)

Distancing himself from literary approaches, both ancient and modern, Zich (perhaps without realising) follows the outline of Poetics, stating that:

An epic work and a drama are different as noetic units, that is to say by nature of their existence, implying different material. It is true that in a novel, for instance, there may exist persons as characters and plot as a struggle, but the persons are described there and the plot is narrated, whereas in a play the persons are represented and the action is performed. It is from this basic difference that all the other differences are derived. The demand that a drama should imply behaviour is not only an indispensable but also a sufficiently adequate condition. (ZICH 1986: 132)

Zich once more just follows in the footsteps of Aristotle, i.e. purporting that plot is not narrated, but represented in action performed by actors. Aristotle did not claim that the art of drama is a literary genre. He only declares that it is above all the art of plot composition, so that it is for the most part the work of the poet, not the actor. Aristotle is only conferring upon literary composition what is rightfully so by saying that even when it is only read, a tragedy can achieve its function or purpose (the two being equivalent in Aristotle's teleological system), which is to arouse the emotions (ARISTOTLE 1987: 41). This is by no means derogatory of theatre production and all of its aspects and components, actors included. Aristotle also considers the theatre public as well as the social elements of the living performance along with the actor [hupokrites]; the best poets would even insert superfluous episodes so the actors could perform a tour de force (ARISTOTLE 1987: 13). The most important qualification of action is that of 'mimesis praxeos'. Aristotle uses the word praxis in its strongest sense, i.e. 'an action which, when represented, forms a whole plot' (ARISTOTLE 1987: 42). 
In comparison with the author of Poetics, Zich emphasizes antagonistic interactivity and conflict, i.e. 'struggle', as he puts it.

'The central conception of dramatic art is human behaviour, which we have defined as such an action of one person which is capable of influencing the action of another person. [...] Dramatic persons are those that act jointly with others and this joint or mutual behaviour of theirs represents the dramatic action'. (ZICH 1986: 132-133; original emphasis)

Zich insists on 'concreteness', that is the visibility and auditivity of the action to be perceived by onlookers, which results in two considerable weaknesses of his theory, namely (1) tethering dramatic action to bodily appearance and the expression of a feeling, and (2) tethering the viewer's mind operations to the level of direct sensory perception, and projecting the meaning image as proceeding only and exclusively from the stage. In this way, Zich seems to forego the various ruminations of the mind about the represented action, the other thoughts incurred by it, the evaluation of each and every aspect, and, finally, judgements and conjectures made concerning future events.

Only its [the dramatic action] basis, perceived by us as the audience, is concrete however: the speech, behaviour and activities of personas which are presented to us also as concrete phenomena by their physical appearance. This experience is supplemented by our own interpretation of these percepts, our referential image, conveying to us the noetic and emotive significance of all the things perceived and thus unfolding the interior of the outer dramatic happenings. (ZICH 1986: 133)

If this bodily appearance is the necessary device and channel of the dramatic conflict, the medium and language is, in consequence, underestimated, and the source of dramatic action is seen predominantly as a feeling, or as two conflicting feelings.

Let us become aware that the acting of person 1 may, in accord with our definition, consist not only of deeds but also general behaviour and speaking, and even the contents of the speech as long as person 1 wants to influence by any of these means person 2, and let us ask what makes person 1 act in this way. The direct cause or motive of acting is always a feeling. [...] A secondary cause is, of course, very often some image or thought, but it must have an emotional colouring. The so-called 'cold approach' has also an emotion for its motive. [...] The popular way of expressing this is 'the discord between reason and feeling'. More precisely said, it is the discord between two feelings, because the idea which is in conflict with the feeling must also have feeling to spring from, which is of course different, with the result that the two endeavours associated with the feelings, are at variance. This condition of mental splitting, although it may figuratively be called conflict, is not yet dramatic as such, i.e. in the same way as a conflict between two persons. (ZICH 1986: 133-135)

Here is an appropriate place to raise an Aristotelian objection. Some conflicts emerge between two persons which convey very scarce emotional content, or the emotional 
element is not as much important as the rational decision and the habit of the represented person. Not only feelings, but character and reasoning (ethos kai dianoia) are the main sources of a dramatic action. Dianoia generally indicates rational thought, yet since poetry is a representation which uses words, in Poetics the term dianoia is employed especially to signify such thoughts expressed in words, which is the way Aristotle uses the term in Rhetoric in its fullest articulation (ARISTOTLE 1987: 8-9). As for characters, they are generally defined by virtues and vices which are expressed in their decisions, along with their reasoning and actions. Unlike passions, the motivations of characters are relatively settled and morally qualified as virtues and vices. According to a certain character we can predict a probability (eikos) indicating a future course of events. If really, as Zich puts it, every dramatic action springs from a feeling, then the whole psychological process of the unfolding of the dramatic action would remain completely unpredictable, as well as the dramatic play in terms of the spectator's expectations which have built on his thoughts about the characters and probabilities that emerge during the performance. For those psychic processes concerning characters and actions (such as remembering, judging or predicting) are not external or contingent; they are performance-connected and induced into spectators' minds by the merit of performance and by means of the inner logic of its dramatic plot.

Zich sets aside the character-type generated probabilities and dismisses to consider a dramatic action:

controlled by will in detail from the intellectual point of view, as the intellectual aspect is often very complicated in plays [...] A characteristic feature of all such acting is the fact that the above-mentioned fused image, which makes the acting person realize the cause and the purpose of his or her doing, also discloses to us, onlookers, the causal final nexus of personal acting, that is to say the inner nexus concerning the acting person alone. This intellectual explanation of the joint problem of 'why he acts like that' and 'with what object in view he acts like that' cannot, however, satisfy us. (ZICH 1986: 135)

At this point Zich clearly attenuates the dianoetic, the intellectual aspect, and adopts the standpoint of Einfühlung aesthetics, which operates with the concept of spectator's empathy based on experience rather than reasoning.

We must find the solution to this joint problem by becoming transfigured with the dramatic perso$n a$ in question. It is the actor's task to induce us to experience it by his suggestive performance. Only then do we understand the acting of the person, no matter how incomprehensible it might seem to us at first sight. The actor has made us understand and believe. (ZICH 1986: 135)

The subsequent analysis of the types of dramatic relations (ZICH 1986: 140-145) is a brilliant example of Zich's analytical approach. Combining the friend/enemy relation with qualities of open/hidden enmity or friendship, he extracts 10 categories of dramatic relations, four symmetrical, and six asymmetrical, and supports his typology with ample evidence from classical drama. Although no direct mention of Aristotle is 
found here, it is evident that Zich draws on Aristotle's deduction of the best type of incidents (ARISTOTLE 1987: 18).

In terms of the unity of personal action, Zich repeatedly uses the italicized expression causal final nexus. Besides its basis on psychological and social law, this expression builds upon the concept of free determination among human purposes (telos, finality), a concept which corresponds with Aristotle in meaning as well as in terminology. Zich, however, stands much more on the side of natural causes for his explanation, whereas Aristotle stresses purpose, reasoning and decision (ARISTOTLE 2014: 39, 2016: 188). This becomes more evident when Zich deals with dramatic randomness and its relation to the lawfulness of the world:

In real life, chance appears to be a sort of violation of the causal nexus which joins the single parts of action, forming at the same time, of course, the first link of a new causal chain. In a work, chance represents the opposite of the acknowledged order in question; it is an irrational element. Owing to the immense importance chance plays in human life we try to rationalize it, i.e. to see in it a manifestation of some metaphysical teleological law. This is all the more reason a playwright must follow this idea in his work, as art in general is expected to present to us perceptually some set of laws governing life [...] while science tackles this problem theoretically. (ZICH 1986: 164)

In Zich's view, it is this 'very general purpose of art to show in a sensible form the lawfulness of the world (in this case the lawfulness of the social human events), which science tries to resolve theoretically' (ZICH 1931: 210, 1986: 164; original emphasis). Aristotle gives more space to randomness and contingency (tuche) in the sublunary sphere, the realm of changing nature. In addition, because drama aims to arouse amazement, in composing a plot even among random events the poet selects those which appear to have happened as they did so on purpose (a 'higher' purpose, the will of gods, etc.) (ARISTOTLE 1987: 13). Nevertheless, there is broad agreement between the two theoreticians about the importance of 'some metaphysical teleological law' that manifests itself from behind contingent human events to the amazement of the viewer.

\section{Conclusion}

We have briefly reviewed a number of salient points of comparison between Zich's and Aristotle's systematic theory of drama. Zich's approach is essentially 'noetic', i.e. from the perspective of a spectator and how the 'semantic image' takes form in his mind; Aristotle's approach is basically 'ontologic', but with regard to the psychological effect on spectator. Zich preferred investigation into the 'analytic principle' of theatre production, which he later identified with 'the inter-play of the living actors on a stage', to any historical explanation of theatre in terms of its origin and development. Zich's crucial differences between the actor and actor-figure, and between the actor-figure and dramatic persona are patently explained in terms of matter and form (hylomophism). 
The concept of finality (teleology) is used in Zich's analysis of dramatic plot, and his demand for 'relative realism' is fully compatible with Aristotelian mimesis, quod erat demonstrandum. From the Aristotelian perspective, however, Zich's description of the process of 'forming significant mental images', both technical and referential, should be complemented by the function of operative intellect, i.e. by a process of reason that by means of these images continuously estimates and judges the dramatic events which are unfolding before his eyes, as well as predicts the images which are feared or hoped for. Without such mental processes, the purification of passions (catharsis) can never take a place. The re-creative perception of the dramatic, which is the essence of drama, depends on aesthesis and noesis, precepts and concepts, the distribution of sympathies and antipathies, remembrances and anticipations, and especially on our judgments. With such an augmentative view concerning the viewer's reflexion, Zich's immortal The Aesthetics of Dramatic Art takes on its full and complete significance.

\section{Bibliography}

ARISTOTLE. 1987. Poetics. Transl. by Richard Janko. Indianapolis: Hackett Publishing Company, Inc., 1987.

ARISTOTLE. 2014. Nicomachean Ethics. Transl. by C. D. C. Reeve. Indianapolis: Hackett Publishing Company, Inc., 2014.

ARISTOTLE. 2016. Metaphysics. Transl. by C. D. C. Reeve. Indianapolis: Hackett Publishing Company, Inc., 2016.

EVANS, J. D. G. 1977. Aristotle's Concept of Dialectic. Cambridge: Cambridge University Press, 1977.

NOVÁK, Bohumil. 1933. Rozhovor s Otakarem Zichem. Čin IV (1933): 20: 465-469.

OSOLSOBĚ, Ivo. 1986. Zichova filozofie dramatického tvaru. In Otakar Zich. Estetika dramatického uměni. Prague: Panorama, 1986: 373-399.

OSOLSOBĚ, Ivo. 2007. Herecká postava - pro a proti [Actor-Figure - For and Against]. In Ivo Osolsobě. Principia parodica. Prague: AMU, 2007: 202-218.

OSOLSOBĚ, Petr. 2003. A Source of Teleological Thinking for the Prague Linguistic Circle. In Marek Nekula (ed.). Prager Strukturalismus. Methodologische Grundlagen. Heidelberg: Universitätsverlag Winter, 2003: 121-133.

ZICH, Otakar. 1931. Estetika dramatického uměni [The Aesthetics of Dramatic Art]. $1^{\text {st }}$ ed. Prague: Melantrich, 1931.

ZICH, Otakar. 1986. Estetika dramatického uměni: teoretická dramaturgie [The Aesthetics of Dramatic Art: A Theoretical Dramaturgy]. $2^{\text {nd }}$ ed. Prague: Panorama, 1986. 


\section{prof. PhDr. Petr Osolsobě, Ph.D.}

Department of Aesthetics, Masaryk University, Arna Nováka 1, 602 00, Brno, Czech Republic

petr@phil.muni.cz

Petr Osolsobě is the head of the Department of Aesthetics at Masaryk University and professor of the Performing Arts at the Janáček Academy of Music and Performing Arts in Brno, the Czech Republic. 